\title{
Who is afraid of more women in politics, and why? An analysis of public opinion in 28 European countries
}

\author{
Giulia Cretti \& Dimiter Toshkov ${ }^{1}$ \\ Institute of Public Administration, Leiden University, the Netherlands
}

This version: 31 August 2021

\begin{abstract}
We study how individual and country-level variables interact in affecting political gender attitudes in Europe. Based on data from the 2017 Eurobarometer survey, we show that there are high levels of support for more women in politics and legal measures to achieve gender parity across the EU. In fact, more people, and women in particular, put higher trust in female compared to male political representatives than the other way round. We find that - at the individual level - gender, age and education have significant effects on political gender attitudes. Contrary to theory, however, the effect of gender is not mediated by beliefs about the proper role of women in politics and society. We also do not find support for the contextual effects of masculine culture and the religiosity of society, but we do uncover significant gaps in political gender attitudes between post-communist and other countries, especially for men. This gap is very significant in size and declines only marginally with the age of the respondent. Our study identifies men in post-communist countries as the group least likely to trust female politicians and support gender parity in politics in Europe. These attitudes are at least partly independent from stereotypes about gender roles.
\end{abstract}

\section{Keywords}

gender, post-communism, political leaders, political stereotypes, public opinion, representation

${ }^{1}$ Corresponding author: d.d.toshkov@,fgga.leidenuniv.nl ORCID: 0000-0002-7444-9340. 


\section{Introduction}

Despite considerable progress in increasing women's participation in politics over the past decades, women still remain under-represented in political life, especially when it comes to positions of political leadership and power. Even in Europe, where progress has been strong, fewer women than men become politicians and are elected as party leaders and political representatives, appointed as ministers and chosen to lead their countries as prime-ministers and presidents (Goddard 2021). Moreover, there is considerable variation in improving women's participation in politics between the European states, with counties from the Northern, Southern and Eastern regions of the continent having rather different trajectories.

The reasons for women's under-representation in politics are diverse and include institutional, cultural and historical factors. Public attitudes, however, play an important role as well: directly, and indirectly by sustaining institutional practices, enacting cultural shared meanings and perpetuating the effects of historical legacies. Therefore, understanding the nature of public attitudes towards the participation of women in politics - what we call political gender attitudes - is important for understanding the reasons for the gender gap in politics and for devising ways of reducing it.

This task, however, is challenging because of the significant variation in political gender attitudes across individuals, across countries and cultural contexts, and across different dimensions of these attitudes. Most existing research has focused on identifying individual-level determinants of support for more women in politics (Alexander \& Jalalzai, 2016; Beauregard, 2016; Bridgewater \& Nagel, 2020). Based on general theories of gender-related prejudice (Bauer, 2020; Dassonneville et al. 2021; de Geus et al. 2021; Piazza \& Diaz, 2020), role congruity (Bauer, 2015; 2020; Eagly, Wood \& Diekman, 2000) and gender affinity (Alexander, 2012; Bridgewater \& Nagel, 2020; Dolan, 2008), we know that females, younger and more educated people are more likely to support wider participation of women in politics. However, how country context moderates these effects and how exactly gender stereotypes mediate them has remained insufficiently studied. Moreover, the strength of these effects can differ depending on the political gender attitude of interest, for example trust in female politicians or support for legal measures to increase women's presence in politics.

In this article, we study how individual and country-level variables interact in affecting three dimensions of political gender attitudes in Europe. Based on data from the 2017 Eurobarometer survey, we show that there are high levels of trust in female political representatives, support for more women in politics and for legal measures to achieve gender parity across the EU. In fact, more people, and women in particular, put higher trust in female compared to male political representatives than 
the other way round. In line with existing knowledge, we find that - at the individual level - gender, age and education have significant effects of political gender attitudes (Alexander \& Jalalzai, 2016; Bauer, 2020; Coffé \& Reiser, 2021; de Geus et al. 2021; Scarborough \& Risman, 2019). Contrary to the theoretical expectations, however, we do not find evidence that the effect of gender is mediated by beliefs about the proper role of women in politics and society (Eagly, Wood \& Diekman, 2000; Garcia-Retamero \& López-Zafra, 2006). We also do not find support for the contextual effects of masculine culture and the religiosity of society, but we do uncover significant gaps in political gender attitudes between post-communist and other countries, especially for men. This gap is very significant in size and declines only marginally with the age of the respondent. Our study identifies men in postcommunist countries as the group least likely to trust female politicians and support gender parity in politics in Europe.

Our main contribution is to show that political gender attitudes are at least partly independent from stereotypes about gender roles. Apparently, strong support for more participation of women in politics can co-exist with stereotypical beliefs that women are less interested in positions of power or that their proper place is at home. The finding about women in more masculine cultures being more likely to have progressive gender attitudes is also novel and important, as it hints at the potential for polarization along gender lines of these attitudes. In methodological terms, our study shows the added value of separating trust in female political representatives as such from trust in politicians irrespective of their gender; the measure of net trust in females - which we introduce - putting political gender attitudes in sharper focus.

\section{Literature review}

Research on female political leadership and representation has significantly expanded in the last decades, in parallel with the continuous increase in the election and appointment of women in political positions. Although the existing literature covers a wide variety of research approaches and theories, this review focuses on two major topics, which emerge repeatedly: gender-related prejudice against female leaders (Bauer, 2020; Dassonneville et al. 2021; de Geus et al. 2021; Eagly \& Karau, 2002; Eagly, Wood \& Diekman, 2000; Piazza \& Diaz, 2020) and the gender affinity effect (Alexander, 2012; Alexander \& Jalalzai, 2016; Beauregard, 2016; Bridgewater \& Nagel, 2020; Dolan, 2008; Liu \& Banaszak, 2017).

\section{Gender prejudice towards female leaders}


A first body of theories of public opinion towards female political leadership is largely focused on gender-related prejudice. These are rooted in social role theory, which is a theoretical framework that seeks to explain the differences and similarities between men and women in social behavior (Eagly, Wood \& Diekman, 2000). Each gender is associated with specific expectations or norms about what a social group can and should do, which in their turn shape the gender role. As a consequence, men and women accommodate to gender roles by pursuing role-related skills.

This process gives rise to a distinction between communal and agentic characteristics. Women are associated with communal behavior focused on the wellbeing of other people, stemming from the domestic female role. Women are thus seen as having strong interpersonal and communication skills and as being more empathetic, compassionate, honest and trustworthy (Eagly \& Karau, 2002; Piazza \& Diaz, 2020). Conversely, men's adaptation to the employment role favors a pattern of association with agentic behaviors, including being more assertive and independent. What emerges from this psychological process of association is the creation of gender stereotypes related to gender-typical occupational roles (Eagly \& Karau, 2002; Eagly, Wood \& Diekman, 2000).

Moreover, "sex segregation of the labor force" sets in motion a mechanism through which perceivers associate a set of typical skills to each gender from observing the type of occupation that is most commonly undertaken by either men or women (Eagly, Wood \& Diekman, 2000, 467). Thus, the fact that more men are employed in jobs that involve agentic behavior leads to the incorporation of the stereotypic of men into a male gender role. This in turn creates expectations which act as normative pressure and foster behavior coherent with gender-typical work roles (Eagly, Wood \& Diekman, 2000).

Based on these assumptions, the role congruity theory of prejudice toward female leaders (Eagly \& Karau, 2002) explains why people are inclined to view women as less qualified than men for leadership positions. It argues that leadership roles are commonly perceived in masculine agentic terms. Thus, since women are associated with communal characteristics, people tend to view them as less suitable than men to become leaders. In other words, there is an incongruity between the social expectations of the leadership role and the feminine gender role (Koenig et al., 2011).

In addition to the role-typicality standards, individuals are influenced by gender stereotypes when they evaluate if a candidate can fulfill a leadership role. Gender stereotypes influence the perception of voters who evaluate political representatives based on the expected competences and skills inherent to their gender. According to the feminine stereotype, women are perceived as less qualified than men to perform roles requiring agentic traits. This influences voters who refuse to view 
women candidates as having the required skills and policy expertise to become political leaders due to a crucial mismatch between the stereotypical female characteristics and the typical skills attributed to a politician. Hence, such role incongruity inevitably creates a disadvantage for female political candidates (Bauer, 2015; 2020; Bridgewater \& Nagel, 2020; Eagly \& Karau, 2002; Lawless, 2004; Simon \& Hoyt, 2008). Note, however, that the stereotypes about male agency do not have a strong effect on how voters judge the governing performance of men and women, with the latter actually receiving less blame and as much credit for the performance (de Geus et al. 2021).

Based on the role congruity theory of prejudice toward female leaders, Garcia-Retamero \& López-Zafra (2006) found that female candidates are generally considered less qualified than men in masculine and gender-neutral working environments. Yet, females are considered to be as effective as male candidates in feminine environments which are more compatible with the feminine gender role.

Recent and innovative studies found that voters judge female party leaders in a more positive way than male ones (Bridgewater \& Nagel, 2020; Cormack \& Karl 2021; Dassonneville et al. 2021). Moreover, at the individual-level, respondents from both sexes tended to view female leaders more favorably than male leaders. This implies that, given the gendered nature of the political environment, voters acknowledge the differences based on gender of political candidates, but there is no evidence regarding voters' preferences for male candidates (Bridgewater \& Nagel, 2020).

\section{Gender affinity effect}

The most common individual-level factor used to investigate public opinion towards female leaders is the gender of respondents. Several studies which include this variable found that female respondents evaluate female leaders more positively than their male counterparts (Alexander, 2012; Alexander \& Jalalzai, 2016; Beauregard, 2016; Bridgewater \& Nagel, 2020). In other words, female respondents have a preference for female candidates (Dolan, 2008). This phenomenon is recurrent and it is refereed as the "gender affinity effect". The literature highlights three main reasons that can explain this effect. First, a feeling of group solidarity may lead women to support female candidates because of a feeling of demographic identification with a candidate of the same gender. Second, since women are still underrepresented in the political arena, female voters may seek descriptive representations by supporting female candidates. Third, recalling social role theory, voters tend to see female candidates as more suited to deal with issues such as child-care, abortion and welfare. Thus, since women voters attribute greater importance to these issues, they will vote for female candidates (Dolan, 2008; Herrnson, Lay, \& Stokes, 2003). 
Other studies focused on the effect of women's leadership positions on political attitudes claim that the presence of female political leaders has a stronger positive impact on women rather than on male respondents (Alexander, 2012; Alexander \& Jalalzai, 2016; Beauregard, 2016; Liu \& Banaszak, 2017). These scholars argue that women's descriptive representation in legislatures (Alexander, 2012, 2015; Beauregard, 2016; O'Brien, 2019), as well in executives (Alexander \& Jalalzai, 2016) has a symbolic effect especially on women as it increases women's trust in women's ability to govern.

\section{Individual and country-level factors affecting public opinion}

Many studies explore the influence of individual-level variables because individual variation in social perceivers can influence the perception of female leaders (Alexander \& Jalalzai, 2016; Bauer, 2020; Coffé \& Reiser, 2021; de Geus et al. 2021). Still, contextual factors, such as culture, are likely to moderate individual public opinion towards female political leaders. Some existing studies compare cross-country attitudes towards women's political leadership and shed light on the strong impact of political culture on the public opinion towards female leaders (Alexander, 2012; Banaszak 2006; Norris \& Inglehart, 2000). Yet, the majority of the above-mentioned works direct little to no attention to the interactions between individual-level and country-level factors in explaining the variation in trust towards male and female political representatives. While they apply a macro-level approach to study public opinion on female political roles and leadership, how the macro level moderates the microlevel forces of public opinion remains relatively understudied.

Moreover, the literature on the influence of gender stereotypes on the perception of political leaders sends an ambiguous message. Existing female leadership theories emphasize the role of gender stereotypes which give rise to a female disadvantage in politics (Bauer, 2015; 2020; Eagly \& Karau, 2002; Lawless, 2004; Simon \& Hoyt, 2008), while more recent research indicates that there is no evidence regarding the existence of a strong voters' preferences for male candidates (Bridgewater \& Nagel, 2020; Cormack \& Karl 2021; Dassonneville et al. 2021).

Regarding the scope of the empirical analysis, most studies focus on the United States or on a single country, while cross-national analysis is relatively lacking. Finally, as the majority of studies focus exclusively on female leaders, there is a gap in the comparison of public opinion for both male and female political representatives, fostering calls in the literature for more comprehensive analysis.

Our contribution to these literatures is to offer a comparison of public opinion towards female political representatives that takes into account opinions on male political representatives by using a new variable called 'net female trust', which measures respondents' difference in the level of trust in 
female and male political representatives. In addition, to address the identified literature gaps, our research investigates the factors which account for the variation in public opinion towards female political leadership by conducting a cross-national analysis of 28 European countries. In particular, we tackle simultaneously individual-level factors - gender, age, education and profession, as well as country-level factors - feminine/masculine culture, religion and communist legacy, in addition to their interactions.

\section{Theoretical hypotheses}

In this section of the article, we derive hypotheses based on the theories and literature reviewed, which we later examine empirically. We formulate the theoretical expectations with regard to the concept of 'political gender attitudes', which we employ as an umbrella concept that captures attitudes and beliefs about the role of women in politics. As we explain below, in the empirical part of the analysis we employ three different variables that capture different aspects of political gender attitudes, namely (a) trust in female political representatives, (b) beliefs that more women should be in politics, and (c) support for legal measures for gender parity in politics.

In accordance with the existing literature, we expect an effect of the gender of respondents on political gender attitudes. This expectation rests on the claim of social role theory that men typically have a more masculine and agentic perception of leadership than women do. Thus, they would be expected to support female leaders less than women do (Alexander \& Jalalzai, 2016; Eagly \& Karau, 2002; Simon \& Hoyt, 2008). Likewise, female citizens will be more likely to exhibit the gender affinity effect and, thus, be more supportive of female candidates (Dolan, 2008). Yet, there are important exceptions which highlight that the opinion on the performance of a female candidate is the same for both male and female respondents (Bridgewater \& Nagel, 2020; Cormack \& Karl 2021; Dassonneville et al. 2021). Additionally, another study shows that women tend to view female candidates as less qualified for leadership positions than men do (Garcia-Retamero \& López-Zafra, 2006). Overall, we suggest the following hypothesis:

Hypothesis 1: Male citizens are less likely than female citizens (a) to trust female political representatives, (b) to believe that more women should be in politics, and (c) to support legal measures for gender parity in politics.

Regarding the age of respondents, there is evidence that it influences the perception of female leaders, and political gender attitudes more generally. Older people are assumed to have a more traditional construal of the female gender role, while younger people tend to support more gender equality (Alexander, 2012; Alexander \& Jalalzai, 2016; Garcia-Retamero \& López-Zafra, 2006; 
Inglehart \& Norris, 2003a; Scarborough \& Risman, 2019). Notably, in postindustrial societies, younger generations have received different formative and social experiences than the older generations. These are expected to have changed the norms regarding the social role of women in the public sphere and the eligibility of female candidates for elected offices (Inglehart \& Norris, 2003a). Thus, the second hypothesis states:

Hypothesis 2: Older citizens are less likely (a) to trust female political representatives, (b) to believe that more women should be in politics, and (c) to support legal measures for gender parity in politics.

Another relevant individual-level variable is education. The literature suggests that the symbolic effect of the increased number of women in parliaments on the trust in women's governing ability is stronger for university respondents (Alexander, 2012). At a more general level, more years spend in the educational system exposes people - directly and indirectly - both to more women in leadership positions and to knowledge about the role women have played in political and social development. For example, Coffé and Reiser (2021) find that increasing knowledge about the actual presence of women in parliament increases support for gender quotas in politics. Education can also undo some of the stereotypes related to 'proper' gender roles and traits 'typical' of men and women. All this is all likely to affect political gender attitudes:

Hypothesis 3: Citizens who spent more years in education are more likely (a) to trust female political representatives, (b) to believe that more women should be in politics, and (c) to support legal measures for gender parity in politics.

Next, the socio-professional context of respondents may influence their level of trust in female leaders. The variable profession is not commonly used in the literature reviewed. However, the study conducted by Eagly \& Karau (2002) shows that male managers perceive their female counterparts as successful as male managers are. Thus, we are interested in investigating whether the political gender attitudes change depending on the profession, assuming that:

Hypothesis 4: Managers are more likely (a) to trust female political representatives, (b) to believe that more women should be in politics, and (c) to support legal measures for gender parity in politics.

Finally, we hypothesize that people who consider themselves to the right on the political leftright spectrum will be less likely to support political gender equality in its various aspects. This is because right-wing political parties tend to espouse more traditionalist and authoritarian viewpoints, which do not allow for much space for women in politics (Bauer, 2017). Such parties aim to decrease the salience of the issue of gender equality in politics and to dismiss calls for wider participation of women in political life, also in positions of leadership. Typically, it is left parties are traditionally 
champions of such issues and positions. Note, however, that the meaning of political left and political right is highly context specific and differs from country to country. In some, it has mostly socioeconomic connotations, while in others it evokes sentiments related to cultural issues, moral permissiveness and nativism. Therefore, it a combined sample with respondents from different European countries, the effect of left-right self-placement can be diluted due to the different interpretations respondents have of these terms. Nevertheless, on average we can observe an association with political gender attitudes. (Political positions could also be partly endogenous to the other socio-demographic variables that we consider.)

Hypothesis 5: Respondent who position themselves to the right of a political left-right scale are less likely (a) to trust female political representatives, (b) to believe that more women should be in politics, and (c) to support legal measures for gender parity in politics.

Now we turn to the mediation hypotheses. According to theory, at least some of the individual-level effects discussed above should be mediated by the beliefs people have about the proper role of women in society and politics and their stereotypes about which tasks and professions women are interested in and suitable for (de Geus et al. 2021; Eagly \& Karau, 2002; Eagly, Wood \& Diekman, 2000). If indeed the effects of the individual-level variables discussed above are exercised through changes in such beliefs, we would expect that once we account for these beliefs in the empirical models, the individual-level effects should disappear or at least get significantly reduced in size. In other words, we would expect that net of their beliefs about the proper role of women in society and politics, men and women, old and young, highly educated and less educated, managers and other professions do not exhibit significant differences in their gender political attitudes anymore.

There are two related but conceptually distinct relevant gender prejudices that could play such a mediating role. The first one is the belief that the most important role of women is to take care of her home and family. This captures general attitudes towards the proper role of women in society and personal life. The second one is more specific to the domain of politics and relates to the belief that women have less interest in political affairs. Such beliefs can be projected to rationalize why people want to limit the presence of women in politics.

Hypothesis 6a: Beliefs about the general role of women in society mediate the effects of the individual-level factors on gender political attitudes.

Hypothesis 6b: Beliefs about the specific interest of women in politics mediate the effects of the individual-level factors on gender political attitudes. 
In addition to the individual-level variables, we study three country-level variables: masculine culture, religiosity and communist legacy. We derive the variable masculine culture from Hofstede's cultural dimensions theory (2011). The dimension "masculinity/femininity" is a societal rather than individual characteristic, which is related to the division of roles and values between men and women. In feminine countries, there is a "minimum social role differentiation between the genders" as they both have the same values (Hofstede, 2011, 12). On the contrary, in masculine countries, there is a strong social role differentiation as men are perceived and expected to be assertive and ambitious while women should be modest and caring. This variable is not commonly used in the empirical research on female leadership, however, we include it in the study because it allows to detect whether countries with stronger descriptive and injunctive norms on gender roles will have a lower level of net female trust (Eagly \& Karau, 2002; Eagly, Wood \& Diekman, 2000). Therefore, we would expect that:

Hypothesis 7: In countries with a more masculine culture, people are less likely (a) to trust female political representatives, (b) to believe that more women should be in politics, and (c) to support legal measures for gender parity in politics.

Second, whether countries have a religious or secular culture is relevant to the level of net trust in women as political leaders. A broad literature suggests that "religion is a primary agent of gender role socialization" (Alexander \& Jalalzai, 2016, 8) and exerts a major influence over people's attitudes and perceptions of gender roles (Alexander, 2012; Inglehart \& Norris, 2003b). In particular, evidence shows that all religious faiths associate women with traditional and subordinate roles, thus having a negative implication for trust in female leaders (Alexander, 2012; Alexander \& Jalalzai, 2016). On the other hand, secularization is associated with a rising tendency of gender equality in politics (Inglehart \& Norris, 2003b; Norris \& Inglehart, 2000). Therefore, we propose the following hypothesis:

Hypothesis 8: In more religious countries, people are less likely (a) to trust female political representatives, (b) to believe that more women should be in politics, and (c) to support legal measures for gender parity in politics.

The third and last country-level variable is communist legacy. The literature shows that Eastern European communist countries were leading examples of gender equality as they encouraged women to enter the workforce to rapidly achieve industrialization. Also, these countries showed high numbers of women in parliaments (Alexander, 2012; Banaszak 2006). Yet, after the fall of communism, they experienced the rise of an antifeminist political culture with the end of quotas for women and a dramatic fall in the percentage of female members of parliament (Alexander, 2012). Furthermore, post-communist countries display more traditional attitudes towards female leadership (Inglehart \& Norris, 2003a; Norris \& Inglehart, 2000). Therefore, we would expect that: 
Hypothesis 9: In post-communist countries, people are less likely (a) to trust female political representatives, (b) to believe that more women should be in politics, and (c) to support legal measures for gender parity in politics.

Finally, we propose that the effect of individual-level variables may vary across countries. Thus, we derive three hypotheses about the interaction effects between individual and country-level variables. According to Norris \& Inglehart (2000), the distribution of attitudes towards women's leadership among generations varies according to the type of country. Notably, in post-industrial countries younger generations have far more egalitarian attitudes than older generations. However, this difference is minimal or absent in post-communist and developing countries (Inglehart \& Norris, 2003a; Norris \& Inglehart, 2000).

Also, we test for an interaction effect between gender and communist legacy. We assume that the general display of more traditional attitudes towards female leadership in post-communist countries (Inglehart \& Norris, 2003a; Norris \& Inglehart, 2000) reinforces the social role theory's assumption that men will trust female representatives less than women do because of a more masculine and agentic perception of leadership (Alexander \& Jalalzai, 2016; Eagly \& Karau, 2002; Simon \& Hoyt, 2008).

Hypothesis 10: In post-communist countries, the negative effects of gender and age on gender political attitudes are stronger.

A different deductive reasoning applies to the effect of gender in countries with a masculine culture. Here, we are interested in assessing whether the gender affinity effect (Dolan, 2008) has a different weight across cultures and countries. Our hypothesis is that in masculine cultures women try to compensate the strong social norms about the gender role (Hofstede, 2011) by endorsing stronger and more positive attitudes towards women in politics. Thus, we expect countries with a masculine culture to exhibit a stronger gender affinity effect (Dolan, 2008) and we therefore propose the following cross-level interaction hypotheses:

Hypothesis 11: In countries with more masculine cultures, the negative effects of gender and age on gender political attitudes are stronger.

\section{Research design, data and method of analysis}

To explore the individual and country-level factors which account for a variation in public opinion towards female political leadership across Europe, we rely upon the Eurobarometer 87.4 survey of public opinion (European Commission, 2019). The survey was conducted in June 2017 in the 28 Member States of the European Union (as of 2017). Data were collected from 28,093 respondents. 
We supplement this dataset with data on masculine culture, religion and communist legacy retrieved from different sources: respectively, the Hofstede Insights indicators (https://www.hofstedeinsights.com); the Special Eurobarometer 341 (European Commission, 2010); and a comparative dataset provided by Armingeon \& Careja (2004).

\section{Outcome variables}

We use three outcome variables to analyze political gender attitudes: net trust in female politicians, belief in the need for more women in politics and support for legal measures for gender parity in politics (European Commission, 2019). These are retrieved from the Eurobarometer 87.4 survey questions as indicated in Table 1. Net female trust measures the difference between trust in female and male leaders on a scale from -3 to +3 , where positive values indicate more trust in female leaders and 0 means equal trust in male and female politicians. The variable more women in politics measures on a scale from 1 to 3 whether people think there should be more or fewer women in politics. Finally, legal measure for gender parity indicates support (or lack of it) for legal measures to ensure parity between men and women in politics (European Commission, 2019).

\section{Individual-level variables}

We select five individual-level variables from the demographic and social characteristics included in the Eurobarometer 87.4 survey: gender, age, education, profession and left-right self-placement. First, gender of respondents is a binary variable, and it is coded 1 for male and 0 for female (European Commission, 2019). Second, age of respondents is measured in years since birth. Third, to assess the educational background, respondents were asked at what age they stopped full-time education (European Commission, 2019). The respondents' profession is operationalized as a binary variable and coded as 1 for managers and 0 for other professions (European Commission, 2019). Left-right self-placement is measured on a scale between left (1) and right (10), which we rescale between -4 and 5 .

\section{Mediating variables}

To analyze possible mediation effects on gender political attitudes, we use two variables: gender stereotypes (general) and gender stereotypes (politics). They are retrieved from the survey questions "Do you agree with the statement: the most important role of a woman is to take care of her home and family?" and "Do you agree with the statement: Women are less interested than men in positions 
of responsibility in politics?". Responses are coded so that higher values indicate a more favorable gender attitude.

\section{Country-level variables}

The Eurobarometer dataset offers a cross-sectional sample of the 28 Member States of the European Union, which allows for a country-level analysis (European Commission, 2017). Our empirical model includes three country-level variables, namely masculine culture, religion and communist legacy. To measure masculine culture, defined as a societal characteristic related to the division of roles and values between sexes (Hofstede, 2011), we rely upon the indicators of the website Hofstede Insights (www.hofstede-insights.com), which provides a percentage of the estimated rate of masculinity for each country in the world. The values range from 1 to 100 . If the value is smaller than $50(\mathrm{x}<50)$, it means the country has a prevalent feminine culture; while if it is larger than $50(\mathrm{x}>50)$, then the country has a dominant masculine culture (Hofstede Insights). The variable religion is defined as the percentage of citizens per country who believe in God (European Commission, 2010; Sägesser et al., 2018). It is retrieved from the Special Eurobarometer 341 on Biotechnology, which presents national percentages of religious belief. Countries with a percentage above $50 \%$ are considered to have a religious culture; on the other hand, countries with a percentage that does not exceed $50 \%$ are considered to have a secular culture (European Commission, 2010).

Table 1. Operationalization of variables

\begin{tabular}{|c|c|c|c|}
\hline Label & Question wording & Original answer scale & Transformations \\
\hline $\begin{array}{l}\text { Net trust in } \\
\text { female politicians }\end{array}$ & $\begin{array}{l}\text { Do you think that a female/male political } \\
\text { representative can represent your interests? }\end{array}$ & $\begin{array}{l}\text { 1-4; Yes, totally to No, } \\
\text { not at all Final variable } \\
\text { ranges }-3 \text { to }+3 \text {. }\end{array}$ & $\begin{array}{l}\text { Scale is inverted and trust in } \\
\text { males is subtracted from trust } \\
\text { in females. }\end{array}$ \\
\hline $\begin{array}{l}\text { More women in } \\
\text { politics }\end{array}$ & $\begin{array}{l}\text { In your opinion, which of the following } \\
\text { statements regarding the number of women } \\
\text { currently in political decision-making } \\
\text { positions in (OUR COUNTRY) applies } \\
\text { best? }\end{array}$ & $\begin{array}{l}\text { 1-3; There should be } \\
\text { more women to There } \\
\text { should be fewer } \\
\text { women }\end{array}$ & $\begin{array}{l}\text { Scale is inverted and rescaled } \\
\text { between }-1 \text { and } 1\end{array}$ \\
\hline $\begin{array}{l}\text { Legal measures } \\
\text { for parity }\end{array}$ & $\begin{array}{l}\text { Are you in favour or against legal measures } \\
\text { to ensure parity between men and women in } \\
\text { politics? }\end{array}$ & $\begin{array}{l}1-4 \text {; Strongly in favor } \\
\text { to strongly against }\end{array}$ & Scale is inverted \\
\hline
\end{tabular}




\begin{tabular}{|c|c|c|c|}
\hline $\begin{array}{l}\text { Gender } \\
\text { stereotypes } \\
\text { (general) }\end{array}$ & $\begin{array}{l}\text { Do you agree with the statement: the most } \\
\text { important role of a woman is to take care of } \\
\text { her home and family? }\end{array}$ & $\begin{array}{l}1-4 ; \text { Totally agree to } \\
\text { totally disagree }\end{array}$ & Scale is inverted \\
\hline $\begin{array}{l}\text { Gender } \\
\text { stereotypes } \\
\text { (politics) }\end{array}$ & $\begin{array}{l}\text { Do you agree with the statement: Women are } \\
\text { less interested than men in positions of } \\
\text { responsibility in politics? }\end{array}$ & $\begin{array}{l}\text { 1-4; Totally agree to } \\
\text { totally disagree }\end{array}$ & Scale is inverted \\
\hline Gender & What is your gender? & 1 Man; 2 Woman & $\begin{array}{l}\text { Coded as binary. } 1 \text { Man; } 0 \\
\text { Woman }\end{array}$ \\
\hline Age & How old are you? & $15-99$ & Divided by 10 \\
\hline Education & $\begin{array}{l}\text { How old were you when you stopped full- } \\
\text { time education? }\end{array}$ & $2-80$ & Divided by 10 \\
\hline Manager & What is your current occupation? & 18 professions & $\begin{array}{l}\text { Coded as binary: } 1 \text { manager; } 0 \\
\text { other professions }\end{array}$ \\
\hline Left-right & $\begin{array}{l}\text { In political matters people talk of "the left" } \\
\text { and "the right". How would you place your } \\
\text { views on this scale? }\end{array}$ & $1-10$ & Rescaled -4 to 5 \\
\hline Masculinity & $\begin{array}{l}\text { Indicator from Hofstede Insights } \\
(\underline{\text { www.hofstede-insights.com }})\end{array}$ & $0-100$ & Divided by 100 \\
\hline Religiosity & $\begin{array}{l}\text { Percentage of citizens per country who } \\
\text { believe in God }\end{array}$ & $0-100$ & Divided by 100 \\
\hline $\begin{array}{l}\text { Communist } \\
\text { legacy }\end{array}$ & Is the country post-communist or not? & $\begin{array}{l}\text { 0: non-comm. legacy; } \\
\text { 1: comm. legacy }\end{array}$ & \\
\hline
\end{tabular}

Finally, the variable communist legacy measures whether countries are post-communist or not (Alexander, 2012). It is interpreted as a binary variable where countries with a communist legacy are coded 1 and all others 0 . This information is retrieved from a comparative dataset for 28 post-communist countries in Europe (Armingeon \& Careja, 2004).

\section{Empirical results}

Before we proceed to testing the hypotheses identified above, we discuss some of the descriptive patterns we find in the data. Details about the average values of all variables per country are provided in the Supplementary Material, Table A1.

\section{Descriptive analysis}


Altogether, in the 28 European countries included in the survey, trust in females as political representatives is rather high. Looking at the bottom-left panel of Figure 1, which plots the (weighted) average of trust in female political representatives per country, we can see that in all countries people tend to trust that a female can represent their political interests. Unsurprisingly, trust is highest in the Nordic countries - Sweden and Denmark, in the Netherlands and Luxembourg, but also in some of the countries in Southern Europe - Spain and Portugal. Trust is lowest, on average, in Slovakia, Italy, Cyprus and Romania. This measure of trust, however, is confounded by general trust in political elites, as manifested in the bottom-right panel of Figure 1, which shows the (weighted) country means for trust in male political representatives. The ranking of countries is quite similar. Therefore, to isolate trust in women in particular, we calculate the difference between trusting a female and a male political representative for each respondent. Taking the country-level average of this new variable results in a different picture, shown in the top panel of Figure 1. Now, the top three countries are Cyprus, France and Italy, while the Eastern European countries are at the other end of the scale. It is noteworthy that only in Latvia, Bulgaria and Romania net trust in female political representatives is below 0 , meaning that the population tends to trust male political representatives slightly more than female ones. In all other countries, the pattern is reversed, with women perceived as (slightly) more trustworthy for being political representatives.

While most respondents $(76 \%)$ have the same level of trust (or distrust) in male and female political representatives, $16 \%$ place more trust (or less distrust) in female politicians, while only $8 \%$ place more trust in male politicians. In other words, twice as many respondents have higher trust in a female to represent their political interests (rather than a male) than the other way round.

Figure 1. Trust in females (bottom left) and males (bottom right) as political representatives in 28 European countries, measured on a scale between 1 and 4. The top panel shows the country-level averages of net trust in female political representatives, calculated at the individual level as the difference between trust in female and trust in male. All country averages are weighted by the survey post-stratification weights. For the translation between ISO-2 country codes and full country names, see Table A1 in the Supplementary material. 


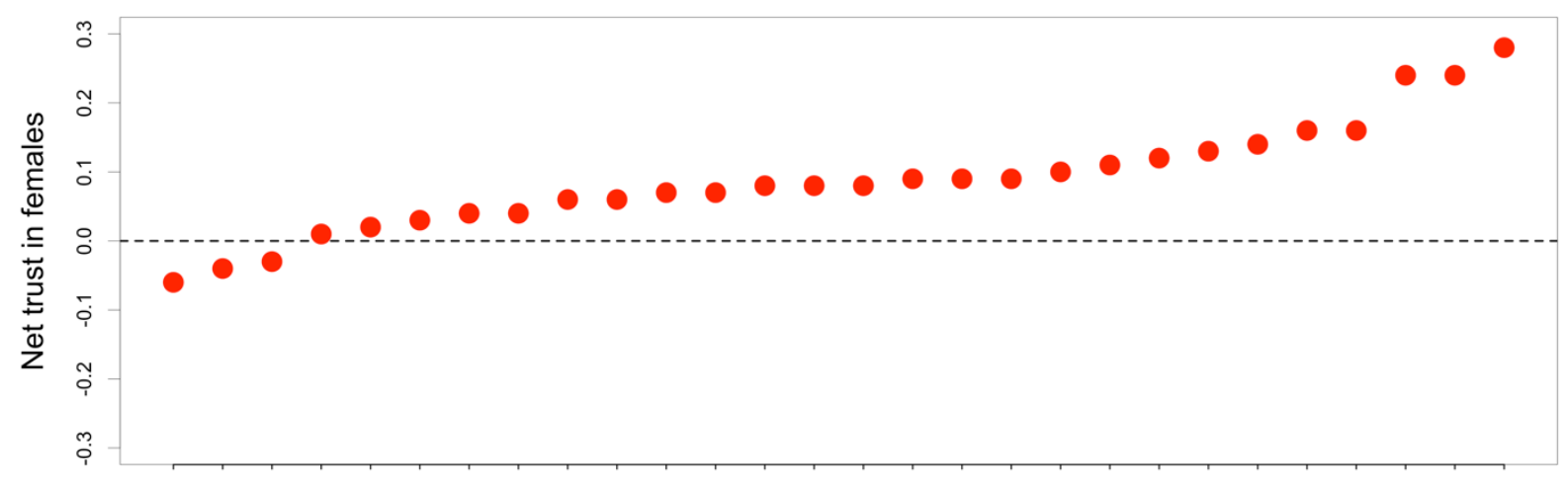

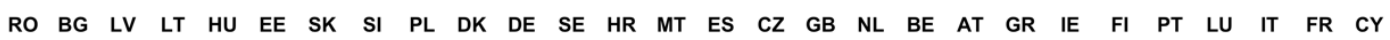
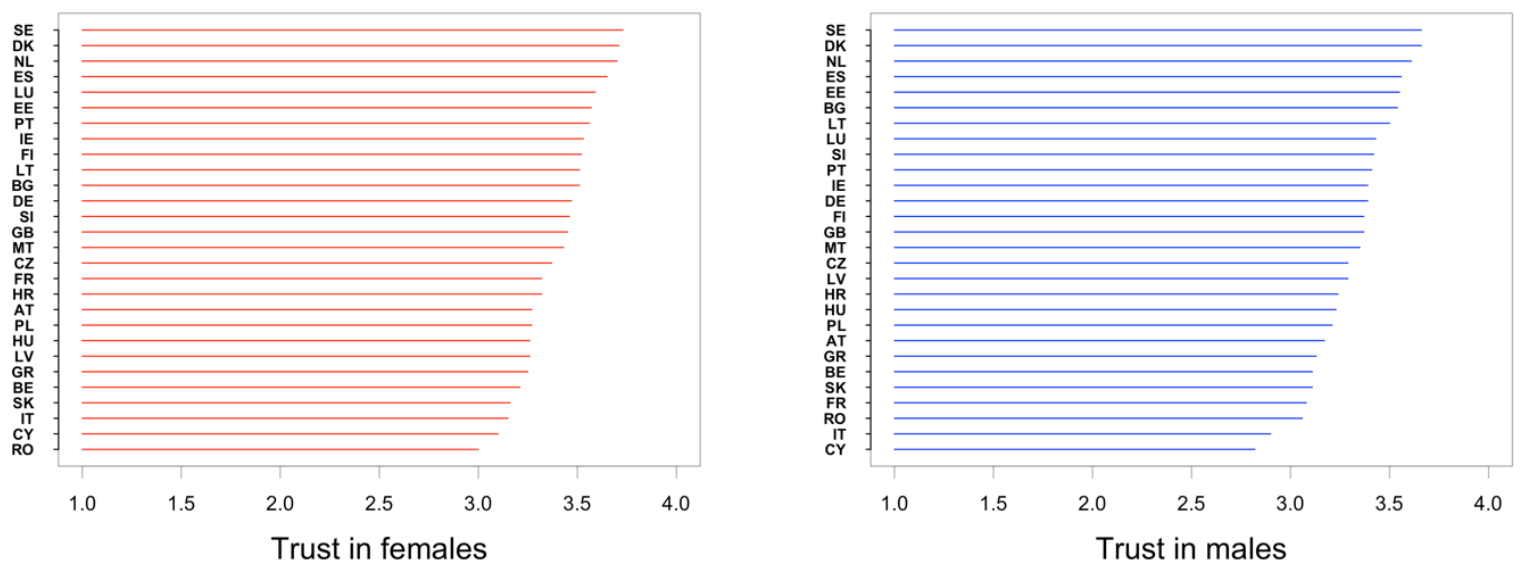

Disaggregating these results by the gender of the respondent, $26 \%$ of women trust a female political representative more than a male one, while only $7 \%$ of men do. A small percentage of women $(4.5 \%)$ trust a man more than a woman as a political representative, while $12.5 \%$ of men do so. All in all, most people think that a male and a female can equally represent their political interests, but from the ones that do not, more people tend to put higher trust in women as political representatives, especially if they are women themselves. The tendency of men to put higher political trust in their own gender is much less pronounced: women are more than twice as likely to have a preference for their own gender than men.

Looking at the other two outcome variables of interest, overall in the combined European sample there is also clear support for the presence of more women in politics. The average value for the full sample is 0.53 (on a scale between -1 and 1), with support being highest in Malta and lowest in Romania (see Table A1). There is also widespread support for legal measures to achieve parity between men and women in politics (average of 3 on the 1-to-4 scale) (cf. Coffé and Reiser 2021 who find low support for positive action measures, such as legal quotas, in Germany). 
At the same time, gender stereotypes are widespread as well. The average support across the full sample for the statement that the most important role of women is to take care of her home and family is 2.53 and for the statement that women are less interested than men in positions of responsibility in politics is 2.27 (both measured on 1-to-4 scales with 'full support' at 4). The highest prevalence of these stereotypes is in Bulgaria and other countries in Eastern Europe, while the lowest prevalence is in Sweden and Denmark.

The descriptive analysis already hints that support for more participation of women in politics can coexist with negative gender stereotypes and that there is significant cross-country variation in these attitudes. The next section of the analysis presents individual-level and multilevel multivariate statistical models that try to account for some of this variation and to disentangle the relationships between socio-economic variables, beliefs in stereotypes and political gender attitudes.

\section{Multivariate statistical models}

We first present the results from the individual-level analysis. Table 2 summarizes six models: for each of the three outcomes variables, we first run a model with the individual-level explanatory factors of interest, and then we add the hypothesized mediators.

As expected, the gender of the respondent has significant negative effects on all three attitudes we study. Being male is associated with a significantly lower likelihood of trusting a female politician more than a male one, of considering that more women in politics are needed, and of supporting legal measures for achieving gender parity in politics. The effects are substantial in size: being male leads to approximately half of a standard deviation change in 'net female trust', one-third of a standard deviation change in 'more women in politics' and one-fifth of a standard deviation change in 'legal measures for parity'.

The effects of education are positive with regard to the first two outcome variables, but there is no effect on support for legal measures for gender parity in politics. The effects of age are, as expected, negative on all three variables, but they are quite small in size (to remind, in Table 2 the coefficients for age and education are for given for a change of 10 years.) 
Table 2. Results from individual-level multivariate linear regression models

\begin{tabular}{|c|c|c|c|c|c|c|c|c|c|c|c|c|c|c|c|c|c|c|}
\hline \multirow[b]{2}{*}{ Predictors } & \multicolumn{6}{|c|}{ (1) Net trust in female politicians } & \multicolumn{6}{|c|}{ (2) More women in politics } & \multicolumn{6}{|c|}{ (3) Legal measures for parity } \\
\hline & Coef. & SE & $p$ & Coef. & SE & $p$ & Coef. & SE & $p$ & Coef. & SE & $p$ & Coef. & SE & $p$ & Coef. & SE & $p$ \\
\hline (Intercept) & 0.17 & 0.06 & $<0.001$ & 0.45 & 0.06 & $<0.001$ & 0.37 & 0.05 & $<0.001$ & 0.71 & 0.05 & $<0.001$ & 3.17 & 0.07 & $<0.001$ & 3.32 & 0.08 & $<0.001$ \\
\hline Gender (male) & -0.30 & 0.01 & $<0.001$ & -0.28 & 0.01 & $<0.001$ & -0.18 & 0.01 & $<0.001$ & -0.17 & 0.01 & $<0.001$ & -0.20 & 0.02 & $<0.001$ & -0.19 & 0.02 & $<0.001$ \\
\hline Education (years*10) & 0.03 & 0.01 & 0.03 & 0.01 & 0.01 & 0.28 & 0.06 & 0.01 & $<0.001$ & 0.04 & 0.01 & $<0.001$ & -0.02 & 0.02 & 0.16 & -0.02 & 0.02 & 0.15 \\
\hline Age (years*10) & -0.01 & 0.00 & 0.01 & -0.00 & 0.01 & 0.36 & -0.02 & 0.00 & $<0.001$ & -0.00 & 0.00 & 0.33 & -0.02 & 0.01 & 0.01 & -0.01 & 0.01 & 0.06 \\
\hline Manager & 0.04 & 0.02 & 0.03 & 0.04 & 0.02 & 0.05 & -0.00 & 0.02 & 0.80 & -0.01 & 0.02 & 0.60 & -0.02 & 0.02 & 0.45 & -0.02 & 0.02 & 0.52 \\
\hline Left-right position & -0.01 & 0.00 & 0.09 & -0.00 & 0.00 & 0.24 & -0.02 & 0.00 & $<0.001$ & -0.01 & 0.00 & $<0.001$ & -0.03 & 0.00 & $<0.001$ & -0.03 & 0.00 & $<0.001$ \\
\hline $\begin{array}{l}\text { Gender stereotypes } \\
\text { (general) }\end{array}$ & & & & -0.04 & 0.01 & $<0.001$ & & & & -0.09 & 0.01 & $<0.001$ & & & & 0.00 & 0.01 & 0.95 \\
\hline $\begin{array}{l}\text { Gender stereotypes } \\
\text { (politics) }\end{array}$ & & & & -0.08 & 0.01 & $<0.001$ & & & & -0.06 & 0.01 & $<0.001$ & & & & -0.07 & 0.01 & $<0.001$ \\
\hline Country indicators & \multicolumn{3}{|c|}{ included } & \multicolumn{3}{|c|}{ included } & \multicolumn{3}{|c|}{ included } & \multicolumn{3}{|c|}{ included } & \multicolumn{3}{|c|}{ included } & \multicolumn{3}{|c|}{ included } \\
\hline Observations & \multicolumn{3}{|c|}{9562} & \multicolumn{3}{|c|}{9108} & \multicolumn{3}{|c|}{9408} & \multicolumn{3}{|c|}{8980} & \multicolumn{3}{|c|}{9269} & \multicolumn{3}{|c|}{8855} \\
\hline $\mathrm{R}^{2} / \mathrm{R}^{2}$ adjusted & \multicolumn{3}{|c|}{$0.060 / 0.057$} & \multicolumn{3}{|c|}{$0.072 / 0.068$} & \multicolumn{3}{|c|}{$0.101 / 0.098$} & \multicolumn{3}{|c|}{$0.132 / 0.129$} & \multicolumn{3}{|c|}{$0.217 / 0.214$} & \multicolumn{3}{|c|}{$0.220 / 0.217$} \\
\hline
\end{tabular}


Being a manager increases the probability that one would trust a female political representative (more than a male one), but has no significant associations with the other two outcome variables. Conversely, the left-right position of the respondent is associated only with the idea that there should be more women in politics and that legal measures should be used to achieve that, but not with net trust.

Unsurprisingly, gender stereotypes have large and significant effects on gender political attitudes. More relevant for our purposes, however, is what happens to the effects of the other individual-level variables, once they are included in the models. Contrary to our expectations, the effect of gender does not change much. In other words, even net of general and politics-specific gender stereotypes, men are much less likely to support all aspects of gender political attitudes. This is not what we would expect based on theory, which posits that ideas about the role of women in society and politics play a crucial mediating role in the formation of gender political attitudes (cf. Eagly \& Karau, 2002).

In line with these theoretical expectations, the effects of age and education indeed disappear completely or get significantly reduced once gender prejudices are included in the models. The effect of being a manager on net trust in female politicians persists, while the effect of left-right position evaporates. However, when it comes to support for more women in politics and legal measures to achieve parity, gender stereotypes do not mediate complete the effect of left-right position.

In Table 3 we report the analyses of the country-level variables and the interactions with the individual-level predictors. Contrary to our hypotheses, as such, masculine culture is not associated significantly with lower support for gender political attitudes. The average level of religiosity of society even increases support for legal measures to achieve gender parity in politics. Only the post-communist legacy has the predicted negative effects. When it comes to the interactions, the effects of gender (being male) are much stronger in more masculine cultures and in post-communist countries when it comes to net trust in female politicians and preferences for more women in politics. However, looking at support for legal measures for parity, the negative effect of being male does not vary significantly with masculinity and post-communist legacy.

The interactions with age, however, do not conform with the hypotheses. Older people in masculine cultures are not less likely to have negative gender political preferences than older people in feminine cultures. If anything, when it comes to support for legal measures to achieve, the negative effect of age in masculine cultures is significantly smaller. Similarly, in post-communist countries the negative effects of age are significantly smaller, for two out of the three outcome variables. 
Table 3. Results from multilevel multivariate linear regression models

\begin{tabular}{|c|c|c|c|c|c|c|c|c|c|}
\hline \multirow[b]{2}{*}{ Predictors } & \multicolumn{3}{|c|}{$\begin{array}{c}\text { (1) Net trust in } \\
\text { female politicians }\end{array}$} & \multicolumn{3}{|c|}{$\begin{array}{l}\text { (2) More women } \\
\text { in politics }\end{array}$} & \multicolumn{3}{|c|}{$\begin{array}{l}\text { (3) Legal measures } \\
\text { for parity }\end{array}$} \\
\hline & Coef. & SE & $p$ & Coef. & SE & $p$ & Coef. & SE & $p$ \\
\hline (Intercept) & 0.34 & 0.09 & $<0.001$ & 0.67 & 0.08 & $<0.001$ & 3.60 & 0.12 & $<0.001$ \\
\hline Gender (male) & -0.07 & 0.03 & 0.03 & -0.07 & 0.03 & 0.01 & -0.25 & 0.04 & $<0.001$ \\
\hline Education (years) & 0.02 & 0.01 & 0.07 & 0.04 & 0.01 & $<0.001$ & -0.18 & 0.02 & $<0.001$ \\
\hline Age (years) & -0.03 & 0.01 & 0.01 & -0.03 & 0.01 & 0.01 & -0.11 & 0.02 & $<0.001$ \\
\hline Manager & 0.04 & 0.02 & 0.07 & -0.01 & 0.02 & 0.69 & -0.01 & 0.03 & 0.75 \\
\hline Left-right position & -0.00 & 0.00 & 0.20 & -0.01 & 0.00 & $<0.001$ & -0.03 & 0.00 & $<0.001$ \\
\hline Masculine culture & -0.00 & 0.14 & 1.00 & 0.19 & 0.12 & 0.11 & -0.26 & 0.19 & 0.16 \\
\hline Religiosity & -0.06 & 0.04 & 0.12 & -0.01 & 0.03 & 0.86 & 0.50 & 0.05 & $<0.001$ \\
\hline Post-communist & -0.06 & 0.07 & 0.35 & -0.36 & 0.06 & $<0.001$ & -0.21 & 0.09 & 0.02 \\
\hline Masculine $*$ Male & -0.44 & 0.06 & $<0.001$ & -0.22 & 0.05 & $<0.001$ & 0.05 & 0.08 & 0.56 \\
\hline Masculine $*$ Age & 0.04 & 0.02 & 0.09 & -0.00 & 0.02 & 0.93 & 0.10 & 0.03 & $<0.001$ \\
\hline Post-communist $*$ Male & -0.15 & 0.03 & $<0.001$ & -0.05 & 0.03 & 0.08 & 0.04 & 0.04 & 0.33 \\
\hline Post-communist $*$ Age & 0.00 & 0.01 & 0.69 & 0.03 & 0.01 & $<0.001$ & 0.07 & 0.01 & $<0.001$ \\
\hline Observations & \multicolumn{3}{|c|}{8216} & \multicolumn{3}{|c|}{8090} & \multicolumn{3}{|c|}{7962} \\
\hline $\mathrm{R}^{2} / \mathrm{R}^{2}$ adjusted & \multicolumn{3}{|c|}{$0.067 / 0.065$} & \multicolumn{3}{|c|}{$0.052 / 0.051$} & \multicolumn{3}{|c|}{$0.128 / 0.127$} \\
\hline
\end{tabular}

Figure 2 illustrates the interaction effects. The left panel plots the predicted probability of net trust in females as political representatives as age varies from 20 to 80 years, based on the estimates from Model 1 in Table 3. As we can see from the figure, net trust declines with age for men (blue lines) as well as for women (red lines), in post-communist (dotted lines) and in other countries (solid lines). The gap between men and women is much greater in the post-communist countries, however, and it remains similar across the values of age. There is a relatively small difference in the gap between the net trust for young women in post-communist and in other countries, which disappears almost complete with age. The gap between the net trust of males in post-communist and other countries is 
huge and remains stable throughout age. In fact, the only group that has on average more trust in male than in female political representatives (negative values on the y-axis) is men in post-communist countries, for all ages.

The right panel of Figure 2 shows the predicted probabilities of support for legal measures to achieve gender parity in politics as a function of age, according to the estimates of Model 3 from Table 3. The patterns here are quite different. In post-communist countries, support for such legal measures increases slightly with age, both for men and women. In the other countries in Western and Southern Europe, however, support for such measures declines significantly with age, again both for men and women.

Figure 2. Predicted probabilities of net trust in females as political representatives (left panel) and support for legal measures for gender parity in politics (right panel) as a function of age. Blue lines show the predicted probabilities for men and red lines for women. Dotted lines are for respondents in countries with a communist legacy, and solid lines in countries without. The predicted probabilities are based on Models 1 and 3 from Table 3 (other covariates fixed at their means).
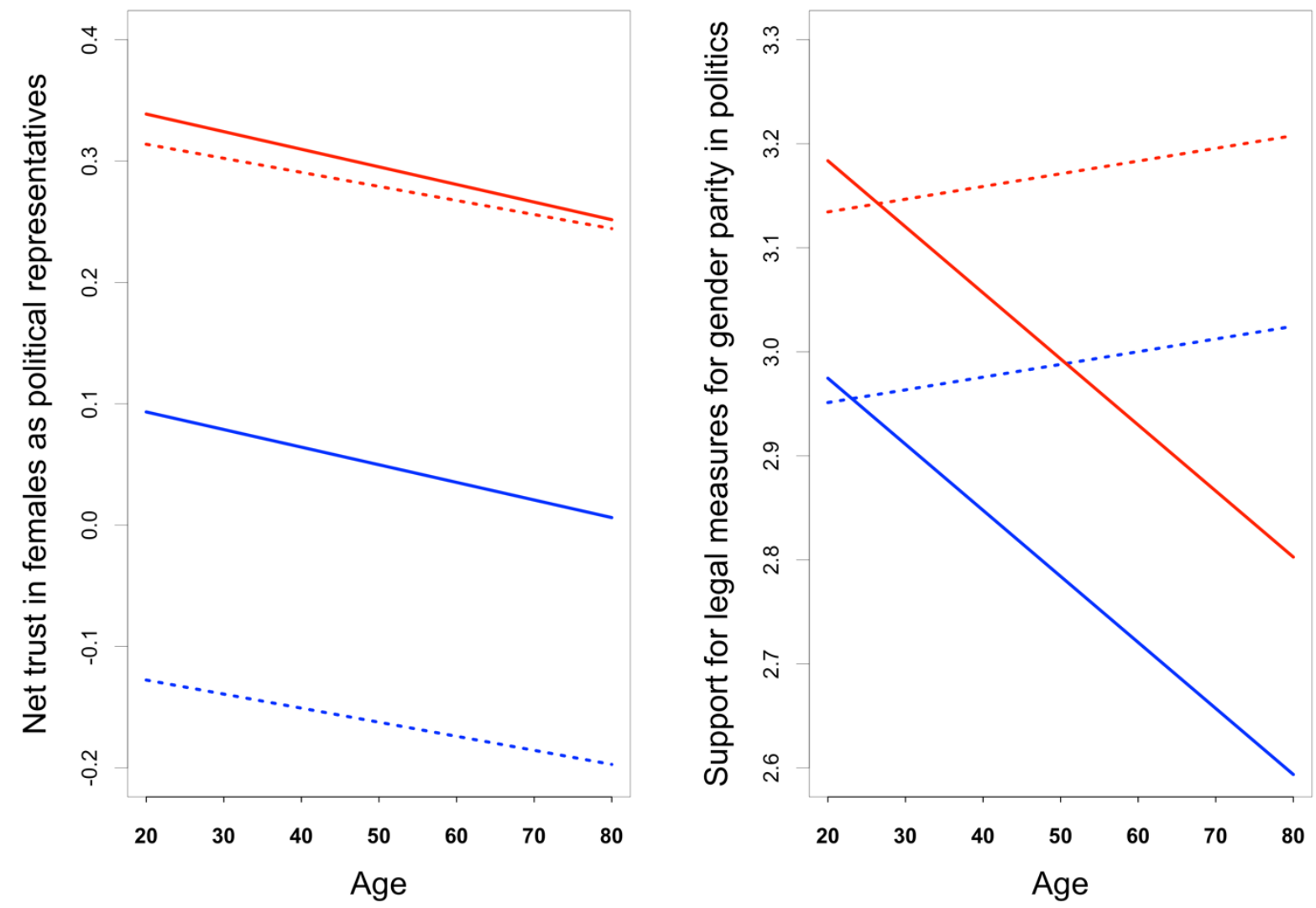


\section{Conclusion}

In this article we analyzed the political gender attitudes of European citizens. Based on existing literature and theories, we formulated a number of hypotheses about individual-level effects on these attitudes and their mediators. We also proposed a number of country-level hypotheses and interaction between individual- and country-level factors. Our empirical results only partially support the theoretical expectations.

First, we should emphasize that we find very high levels of trust in women as political representatives, as well as support for more women in politics and legal measures to achieve gender parity. In fact, more people would trust a female as a political representative rather than a male than the reverse, especially among women themselves. These high levels of trust and support hold for the EU-28 sample as a whole, but also in the vast majority of individual countries, with very few exceptions in Eastern Europe. This is consistent with recent findings from the US that the public evaluates women politicians more highly than men (Cormack and Karl 2021), but the mechanism is likely to be different than this article proposes - partisanship (see also Bridgewater \& Nagel, 2020; Dassonneville et al. 2021).

Second, we do find the expected effects of gender, age, and education on political gender attitudes (Alexander \& Jalalzai, 2016; Bauer, 2020; Coffé \& Reiser, 2021; de Geus et al. 2021; Scarborough \& Risman, 2019). The effects of professional background and political ideology are more variable across different outcome variables and not always significant (cfr. Bauer, 2017).

Third, and most importantly, however, the effect of the respondent's gender in particular persist even after we include measures of general and politics-specific gender-stereotypical beliefs in the models. In other words, men are significantly less likely to trust females as political representatives, agree that we need more women in politics and support legal measures to achieve parity even after controlling for their beliefs about the proper role of women in society and their (dis)interest in positions of political leadership. This result is unexpected in terms of the theories that predict that political gender attitudes are based on such perceptions about what women want and should be doing (Bauer, 2020; Eagly \& Karau, 2002).

Fourth, from the country level variables that we examine, masculine culture and the level of religiosity do not have the expected negative main effects (cfr. Inglehart \& Norris, 2003b). This could be due to the fact that in such countries - for example in Spain and Portugal - women have mobilized against traditional discourses rooted in the national culture and religion that restrict their roles in 
politics. So, the effects of culture and religion are counteracted by the backlash of political mobilization in favor of more women in politics and in positions of political power.

The legacy of communist, however, continues to have a very strong effect on political gender attitudes (Alexander, 2012; Inglehart \& Norris, 2003a), especially among men living in the postcommunist countries in Eastern Europe. To some extent this is quite surprising, not only because more than 30 years have now passed since the fall of communism in Europe, but also because actual levels of participation of women in politics and business life are not too low, even if they fall short of the highest levels observed in the Nordic countries. Many of these countries have had female primeministers, deputy prime-ministers, ministers, chairs of the legislatures, and party leaders. (This is consistent with the result of Costa and Wallace 2021 that women's presence does not influence significantly their perceived political efficacy or the likelihood to vote for female candidates.) Still, men in post-communist countries, in particular, exhibit low trust in females as political representatives and do not think that more women in politics are needed, let alone legal measures to achieve that.

It is also noteworthy that the gap between respondents in post-communist and other countries does not disappear with age (Inglehart \& Norris, 2003a; Norris \& Inglehart, 2000), again especially for men. While younger men have more favorable political gender attitudes, the effect of age is relatively small and does very little to close the gap with Western and Southern Europe, and the gap between men and women within Eastern Europe as well. This result has an important policy implication: active measures are needed to increase trust in female politicians and support for gender equality in politics in the post-communist countries; these changes would not come simply as new generations come and older generations retire.

Another policy implication of our work is that correcting negative gender stereotypes (such as women are not interested in positions of political power or that their place is at home) would not close the gap in political gender attitudes between men and women. As the mediation analyses show, the gap remains just as wide even after gender stereotypes are taken into account.

One important limitation of our work is that it only taps into attitudes and opinions, and we cannot say much about how such attitudes and opinions translate into actual relevant behaviors, such as voting for female political candidates or taking political actions for gender parity in politics. We also only look at one snapshot in time, and we miss how the relationships we study develop over time, both in terms of descriptive trends and in terms of causal effects.

Future research can address these limitations by linking opinion data to behavioral data on voting in particular, but also on various forms of political action, such as participation in 
demonstrations, petitions, and other forms of political activism. The research should also be extended to other countries in Europe and beyond where baseline levels of support for political gender equality and trust in female politicians are much lower than observed in the $28 \mathrm{EU}$ members that we study. In these different context, the determinants of gender political attitudes might be quite different, but their substantive importance could be even greater.

\section{References}

Alexander, A. C. (2012). Change in Women's Descriptive Representation and the Belief in Women's Ability to Govern: A Virtuous Cycle. Politics \& Gender, 8(4): 437-434.

Alexander, A. C., and Jalalzai, F. (2016). The Symbolic Effects of Female Heads of States and Government. In The Gendered Executive: A Comparative Analysis of Presidents, Prime Ministers, and Chief Executives, edited by Janet M. Martin and MaryAnne Borrelli. Philadelphia: Temple University Press.

Armingeon, K., \& Careja, R. (2004). Comparative Data Set for 28 Post-Communist Countries, 1989-2004, Institute of Political Science, University of Berne.

Banaszak, L. A. (2006). Gendering the State and Citizen's Attitudes towards Women's Roles. Politics \& Gender, 2(1): 29-55.

Bauer, N. M. (2015). Emotional, sensitive, and unfit for office? Gender stereotype activation and support female candidates. Political Psychology, 36(6): 691-708.

Bauer, N. M. (2017). The Effects of Counter-Stereotypic Gender Strategies on Candidate Evaluations. Political Psychology, 38(2): 279-295.

Bauer, N. M. (2018). Untangling the Relationship Between Partisanship, Gender Stereotypes, and Support for Female Candidates. Journal of Women, Politics \& Policy, 39(1): 1-25.

Bauer, N. M. (2020). Shifting standards: How voters evaluate the qualifications of female and male candidates. The Journal of Politics, 82(1), 1-12.

Beauregard, K. (2016). Women's Representation and Gender Gaps in Political Participation: Do Time and Success Matter in a Cross-national Perspective? Politics, Groups, and Identities, 6(2): 237-263.

Bridgewater, J., \& Nagel, R. U. (2020). Is there cross-national evidence that voters prefer men as party leaders? No. Electoral Studies, 67, 102209.

Coffé, H. and Reiser, M. (2021) 'How perceptions and information about women's descriptive representation affect support for positive action measures', International Political Science Review. 
Cormack, L., \& Karl, K. (2021). Why Women Earn High Marks: Examining the Role of Partisanship and Gender in Political Evaluations. Politics \& Gender, 1-30.

Costa, M. and Wallace, I. (2021) 'More Women Candidates: The Effects of Increased Women's Presence on Political Ambition, Efficacy, and Vote Choice', American Politics Research, 49(4), pp. 368380.

Dassonneville, R., Quinlan, S., \& McAllister, I. (2021). Female leader popularity and the vote, 19962016: a global exploratory analysis. European Journal of Politics and Gender, 4(2).

de Geus, R. A. et al. (2021) 'Do Voters Judge the Performance of Female and Male Politicians Differently? Experimental Evidence from the United States and Australia', Political Research Quarterly, 74(2), pp. 302-316.

Dolan, K. (2008). Is there a "gender affinity effect" in American politics? Information, affect, and candidate sex in US House elections. Political Research Quarterly, 61(1): 79-89.

Eagly, A. H., \& Karau, S. J. (2002). Role congruity theory of prejudice toward female leaders. Psychological Review, 109(3): 573-598.

Eagly, A. H., Wood, W., \& Diekman, A. B. (2000). Social role theory of sex differences and similarities: A current appraisal. The developmental social psychology of gender, 12, 174.

European Commission. (2010). Special Eurobarometer 341, Biotechnology, Report.

European Commission. (2017). Special Eurobarometer 465, Gender Equality, Report.

European Commission. (2019): Eurobarometer 87.4 (2017). TNS opinion, Brussels [producer]. GESIS Data Archive, Cologne. ZA6924 Data file Version 1.0.0,

Garcia-Retamero, R., \& López-Zafra, E. (2006). Prejudice against Women in Male-congenial Environments: Perceptions of Gender Role Congruity in Leadership. Sex Roles, 55(1-2): 51- 61.

Goddard, D. (2021) 'Examining the appointment of women to ministerial positions across Europe: 1970-2015', Party Politics, 27(4), pp. 631-643.

Herrnson, P. S., Lay, J. C., \& Stokes, A. K. (2003). Women running “as women”: Candidate gender, campaign issues, and voter-targeting strategies. The Journal of Politics, 65(1): 244- 255.

Hofstede, G. (2011). Dimensionalizing Cultures: The Hofstede Model in Context. Online Readings in Psychology and Culture, 2(1). 
Hofstede Insights. Compare countries. https://www.hofstede-insights.com/product/comparecountries/

Inglehart, R., \& Norris, P. (2003a). Women as Political Leaders. In Rising Tide: Gender Equality and Cultural Change Around the World (pp. 127-146). Cambridge: Cambridge University Press. doi:10.1017/CBO9780511550362.007

Inglehart, R., \& Norris, P. (2003b). Religion, Secularization, and Gender Equality. In Rising Tide: Gender Equality and Cultural Change Around the World (pp. 49-72). Cambridge: Cambridge University Press. doi:10.1017/CBO9780511550362.004

Koenig, A. M., Eagly, A. H., Mitchell, A. A., \& Ristikari, T. (2011). Are leader stereotypes masculine? A meta-analysis of three research paradigms. Psychological bulletin, 137(4): 616- 642.

Lawless, J. L. (2004). Women, war, and winning elections: Gender stereotyping in the post- September 11th era. Political Research Quarterly, 57(3): 479-490.

Liu, S. S., and Banaszak, L. A. (2017). Do Government Positions Held by Women Matter? A CrossNational Examination of Female Ministers' Impacts on Women's Political Participation. Politics \& Gender, 13(1): 132-162.

Norris, P., \& Inglehart, R. (2000). Cultural Barriers to Women's Leadership: A Worldwide Comparison. Paper for Special Session 16 'Social Cleavages and Elections' at the International Political Science Association World Congress, Quebec City.

O'Brien D. Z. (2019). Female leaders and citizens' perceptions of political parties. Journal of Elections, Public Opinion and Parties, 29(4): 465-489.

Piazza, K. S., \& Diaz, G. (2020). Light in the midst of chaos: COVID-19 and female political representation. World Development, 136, 105125.

Sägesser, C., Nelis, J., Schreiber, J. P., \& Vanderpelen-Diagre, C. (2018). Religion and secularism in the European Union. Observatory of Religions and Secularism (ORELA) Report.

Scarborough, W. J., Sin, R., \& Risman, B. (2019). Attitudes and the stalled gender revolution: Egalitarianism, traditionalism, and ambivalence from 1977 through 2016.Gender \& Society, 33(2), 173200.

Simon, S., \& Hoyt, C. L. (2008). Exploring the gender gap in support for a woman president. Analyses of Social Issues and Public Policy, 8(1): 157-181. 
Supplementary material 
Table A1. Descriptive information about the variables used in the analysis.

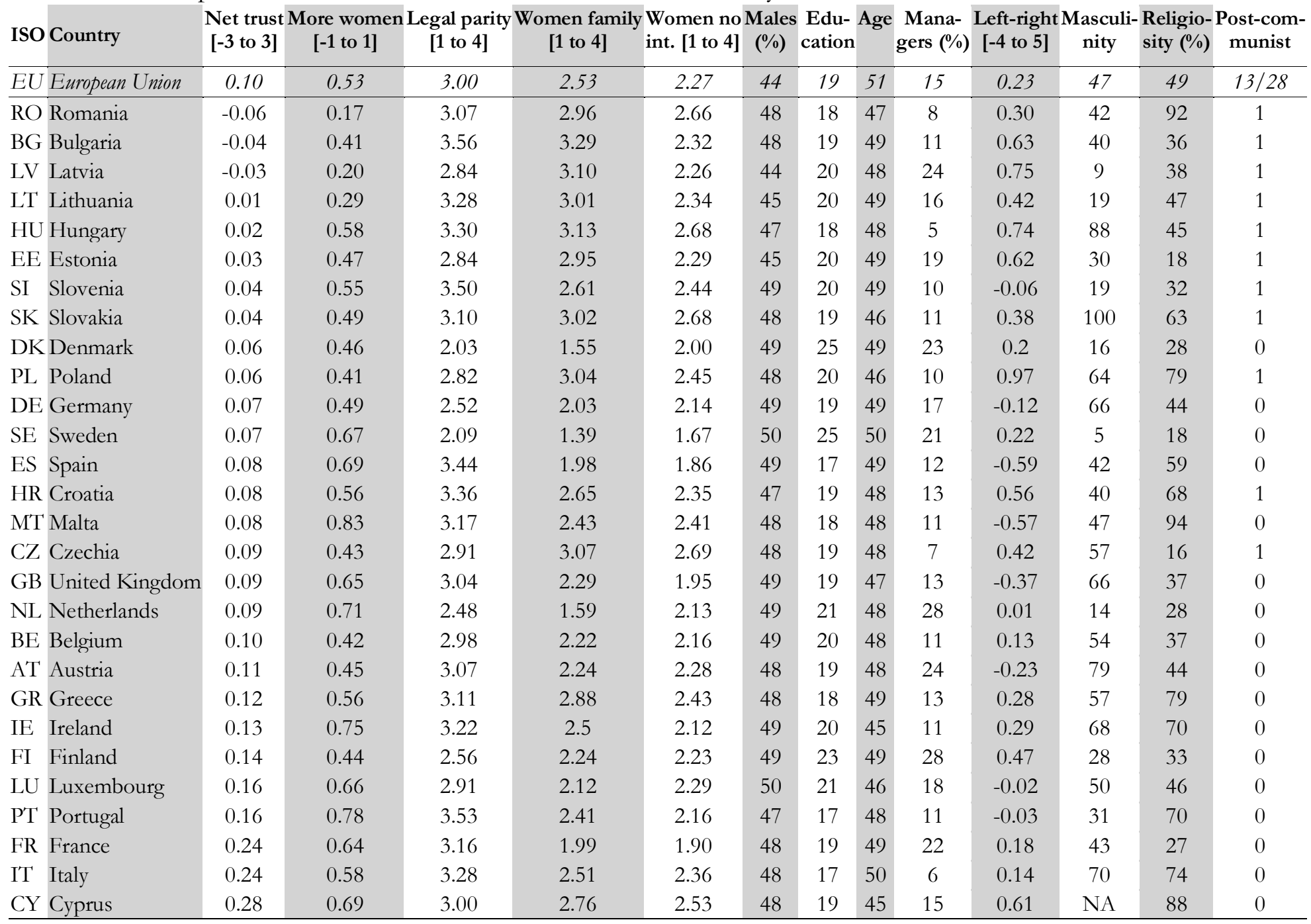

Notes: All aggregates of individual-level variables from Eurobarometer 87.4. Country means are weighted by survey post-stratification weights. 